\title{
COVID-19: Making the Best out of a Forced Transition to Online Medical Teaching-a Mixed Methods Study
}

\author{
Montserrat Virumbrales $^{1} \cdot$ Marta Elorduy $^{1} \cdot$ Mariona Graell $^{2} \cdot$ Pau Mezquita $^{1} \cdot$ Pedro Brotons $^{1,3,4}$. \\ Albert Balaguer ${ }^{1,5}$ ()
}

Accepted: 2 February 2022 / Published online: 23 February 2022

(c) The Author(s) under exclusive licence to International Association of Medical Science Educators 2022

\begin{abstract}
Introduction The first wave of the COVID-19 pandemic resulted in a decreed confinement in Spain from March until the end of term in June 2020, forcing an abrupt transition to exclusive distance learning in universities. We aimed to describe and analyze the perceptions and experiences of undergraduate medical students and faculty members as a consequence of this educational shift so as to identify the key elements for successful online medical learning.

Methods A convergent mixed methods design was employed, using both quantitative and qualitative data collected successively through Phase 1: Online teaching follow-up program; Phase 2: Discussion groups (two focus groups and a nominal group with students and faculty, respectively) and a survey of students from first to fifth year; and Phase 3: Triangulation of qualitative and quantitative data.

Results Thirteen strongly interconnected categories were identified. Four of them played an organizational role: course planning, coordination, communication, and pedagogical coherence. The remaining nine categories were learning outcomes, teaching methodology, online resources, evaluation, time management, workload, student motivation, participation, and teacher-student relationship. Among the key aspects of learning were those that promoted rapport between faculty and students, such as synchronous sessions, especially those based on clinical cases.

Conclusions Promoting student motivation and participation at all levels were the main lessons learned for enhancing online learning and teaching experiences in undergraduate medical education. Key elements to reach this goal are, among others, planning, coordination, communication, and pedagogical coherence.
\end{abstract}

Keywords COVID-19 $\cdot$ Education $\cdot$ E-learning $\cdot$ Medical $\cdot$ Undergraduate $\cdot$ Students

Montserrat Virumbrales and Marta Elorduy contributed equally to the study as first co-authors.

Albert Balaguer

abalaguer@uic.es

1 Department of Medicine, School of Medicine and Health Sciences, Universitat Internacional de Catalunya, C. de La Inmaculada, 22, 08017 Barcelona, Spain

2 Department of Education, School of Education, Universitat Internacional de Catalunya, Barcelona, Spain

3 Institut de Recerca Sant Joan de Déu, Barcelona, Spain

4 Consorcio de Investigación Biomédica en Red de Epidemiología y Salud Pública (CIBERESP), Madrid, Spain

5 Hospital Universitari General de Catalunya, Barcelona, Spain

\section{Introduction}

The novel coronavirus-19 infectious disease (COVID-19) pandemic has dramatically changed the economic, social, and daily life of millions of people worldwide since it emerged in Wuhan, China, in December 2019 [1]. One of the countries most affected by COVID-19 has been Spain, with 4,988,878 cases and 87,030 deaths confirmed as of October 21, 2021 [2]. A state of emergency was declared by the national government on March 14, 2020, imposing strict confinement for the population and closure of most businesses and all leisure, cultural, and educational places across the country. As the first wave of the pandemic slowly began to recede, confinement was gradually eased until the complete lifting of lockdown restrictions on June 21.

The disruption of learning activities has particularly impacted undergraduate medical education, an academic field 
where practical skill acquisition and collaborative training experiences become central [3-5]. While clinical clerkships constitute the primary learning format in the final phase of the undergraduate medical curriculum, face-to-face modalities are essential to acquire basic knowledge and competences at initial stages. As a consequence of the critical situation caused by the pandemic, a number of programmed clinical clerkships had to be urgently readjusted so that senior undergraduates could give support to the clinical management of COVID-19 at a diversity of primary care centers and hospitals. In contrast, lockdown of schools of Medicine resulted in face-to-face learning becoming suddenly halted at initial undergraduate courses. In addition, university faculty, most of which were also deeply involved in the healthcare provision to COVID-19 patients, were committed to transforming face-to-face learning to a virtual format with little or no previous experience in distance learning environments. Boards of medical schools across the nation faced compelling challenges to replace or combine in-person learning with online formats while addressing students' needs and expectations, in anticipation of future scenarios of potential COVID-19 re-emergence. However, little is known about the effects of such measures.

The Universitat Internacional de Catalunya (UIC) School of Medicine is an academic institution located in the metropolitan area of Barcelona (Spain) that has a strong commitment to educational innovation and extensive adoption of technology-based learning methods. The school enrolls 100 new medical students every year and offers a fully integrated medical curriculum from first to fifth year that includes clinical rotations (third to fifth year) and a final clerkship in the sixth year. Due to the interruption of all face-to-face academic activities related with the UIC degree in Medicine, out of the total amount of teaching activities traditionally carried out in classrooms, including laboratories and simulation rooms, approximately $60 \%$ took place using live online platforms, whereas the remaining $40 \%$ was provided in prerecorded format. Additionally, the use of virtual classroom activities was encouraged at all levels, particularly those that promoted active student involvement such as games and apps, pop quizzes, and online tutoring of individual or group projects. An effort was made to ensure that students had the technical means to access the teaching materials on the virtual learning platform, while making sure that these materials contained the necessary resources adapted to the specific situation (short videos, audio-embedded presentations, external resources, etc.). In addition, communication channels were tightened between students, student delegates (2 per year), faculty, and the Dean's Office (DO).

In the midst of this process, we were interested in finding ways to analyze the outcomes of such deep and abrupt changes in the teaching and learning experience. Identifying the lessons learned from this unplanned teaching revolution became crucial to better prepare faculty members for future scenarios in which full on-campus medical education may not be feasible. It also constituted a great opportunity to incorporate the best online practices as complements to face-to-face education once a scenario of normality could be recovered. Taken all this into account, we set out to carry a study with two objectives: (a) to describe and analyze the perceptions and experiences of faculty members and undergraduate medical students as a consequence of switching from on-campus to full online education following the country-wide COVID-19 confinement, and (b) to identify the key elements that need to be addressed in successful online medical learning.

\section{Materials and Methods}

\section{Study Design and Participants}

A single-center prospective study was conducted with undergraduate students from first to fifth year (excluding the students of sixth year, who were doing clinical clerkships) and faculty members at UIC School of Medicine during the months from April to July of 2020. The study was conducted through 3 phases using a convergent mixed methods approach that involved the collection, analysis, categorization, and triangulation of both qualitative and quantitative information [6-8].

\section{Phase 1: Online Teaching Follow-up Program}

Upon the inception of confinement, the UIC School of Medicine established an online teaching follow-up program as an instrument for periodical collection of qualitative information provided by medical students and faculty in relation to methodology, faculty communication, student assistance, and satisfaction. The instrument aimed at meeting the needs of both groups and to ensure that the learning objectives were achieved. Through this follow-up program, three members of the DO continuously monitored the evolving situation and made decisions whenever changes were required. The instrument relied on the monitoring of a set of key elements gathered from (a) periodic meetings held separately with faculty, student delegates, and representatives of student organizations; (b) a cloud-based registry of incidents for each subject of the curriculum that was weekly updated and shared between the DO, subject coordinators, and student representatives; and (c) a periodic meeting between the DO and a group of student delegates of all academic years to make adjustments to methodology, workload, and evaluation criteria. Diverse actions were taken on the basis of information collected through the follow-up program, including faculty training in digital skills, provision of online resources to 
students in need, and setup of agile communication channels between students, faculty, and the DO.

Perceptions, suggestions, and incidences derived from the implementation of online teaching were documented in Google Drive files that were shared with students' representatives and faculty. Feedback from students and faculty was specifically requested about adequacy of online methodologies, smoothness of communication between students and faculty and staff, student satisfaction with assistance received from faculty, and overall coordination. Weekly analysis of the data gathered through the follow-up program allowed the DO to monitor the evolution of online teaching and make timely decisions to ensure fulfilment of learning objectives.

\section{Phase 2: Discussion Groups and Survey}

The points for improvement identified through the online follow-up program, together with the review of the relevant academic literature on the theory of higher education [9-11], constituted the basis for defining the scripts to conduct focus and nominal group discussions with students and faculty, respectively, as well as the questions of an online survey with students (see Supplementary File 1-Script for discussion in the focus groups, Supplementary File 2-Script for discussion in the nominal group, and Supplementary File 3-Survey Questionnaire).

\section{Discussion Groups}

Two focus group discussions were carried out with 22 purposely chosen medical students from first to fifth year. The criteria for selection of participants aimed at ensuring the highest plurality in terms of gender, age, academic year, and learning performance, as well as implication with the DO. One group with nine first- and second-year medical students and another group with 13 third-, fourth-, and fifthyear medical students were set up. Since data saturation was reached during discussions, the possibility to run additional focus groups was discarded.

On the other hand, one nominal group discussion was held with eight faculty members from first to fifth year that were participating in distance teaching during confinement. Selected faculty members were representative of diverse fields of knowledge and had various levels of teaching expertise and digital skills, which guaranteed the required heterogeneity within the group. Their ages ranged from 40 to 62 years and there was a men to women ratio of 3:1, similar to the proportion found among faculty members of the UIC degree in Medicine.
Distance learning experiences lived by students and faculty were interpreted from the perspective of their protagonists [12]. Focus and nominal group meetings were conducted online and video recorded using the Google Meet platform, literally transcribed, and analyzed qualitatively using the Atlas-ti version 8.4.4 software.

\section{Survey}

An anonymous online survey was conducted with medical students from first to fifth year who had received on-campus education until confinement. The survey questions addressed the following aspects: activities used in online teaching; students' motivations, expectations, prioritizations, and recommendations; positive and negative aspects of online methodology implementation; communication methods; good and bad practices; and a global opinion on the teaching and learning experience. Prior to its launch, the survey was reviewed by the team of researchers for understanding and refinement of wording. Responses to the online survey were rated on a Likert scale of 1 to 5 (ranging from "worst" to "best") or classified in a binary format and summarized as average scores or proportions using Stata v.15.1 software (Stata Corp., USA).

\section{Phase 3: Triangulation of Qualitative and Quantitative Data}

Data triangulation was performed to confirm the results concurrently and simultaneously collected in the two processes of Phase 2 so as to achieve the objectives of the study. Analysis, interpretation, and triangulation of data was carried out independently by three researchers and later shared through discussion to validate the information. Exploitation of these data aimed at identifying the key elements for online learning.

\section{Results}

\section{Quantitative Analysis}

The survey conducted among students $(n=483)$ obtained a $50.5 \%$ response rate $(n=244)$. Students from first and second years rated distance learning as "acceptable" (average score 3.1/5), while those in third, fourth, and fifth years rated it slightly below (2.7/5).

A total of $63.1 \%$ of students stated that they had "learned less" with online teaching compared to face-to-face interaction. The worst rated aspect was the additional student workload involved in distance learning (0.7/5). Some other poorly valued aspects were teacher-student relationship (2.1/5), motivation (2.3/5), planning (2.6/5), pedagogical 
coherence (2.6/5), and participation (2.9/5). The aspects that received the highest scores for optimized learning were lectures carried out using synchronic communication tools (3.9/5) and case-based teaching (3.4/5). Further details of quantitative results are described elsewhere [13].

\section{Qualitative Analysis}

The main concerns expressed by students through the online teaching follow-up program were lack of motivation, improvable coordination, and insufficient communication. Faculty members showed primary concerns on the difficult adaptation to online methodologies and the lack of digital skills. This information, along with the review of the literature, allowed the identification of the following key teaching aspects: pedagogical coherence, learning outcomes, teaching methodologies, participation, role of teacher, role of student, teacher-student relationship, evaluation, student motivation, coordination, communication, adaptation to the new methodologies, and lack of digital skills.

On the other hand, the outcomes obtained in discussion groups delimited 13 categories, nine of which coincided with the key teaching aspects previously identified (pedagogical coherence, learning outcomes, teaching methodologies, participation, teacher-student relationship, evaluation, student motivation, coordination, and communication) and four were ruled out according to their minor significance measured by the low number of citations (role of teacher, role of student, adaptation to the new technologies, and lack of digital skills). In addition, four new categories emerged, namely course planning, time management, work load, and online resources. Table 1 shows the 13 categories and includes their detailed description and the number of citations for each category. Of note, specific categories (coordination, workload, student motivation, and teaching methodologies) contain subcategories due to the need to classify the qualitative data with precision.

Table 1 Categories, descriptors, subcategories, and number of quotations obtained from qualitative analysis of discussion groups with faculty and students

\begin{tabular}{|c|c|c|c|}
\hline Key categories & Description & Subcategories & $\begin{array}{l}\text { No. of } \\
\text { quotations }\end{array}$ \\
\hline Course planning & $\begin{array}{l}\text { Identifying the learning objectives. Designing the activities, assessments, } \\
\text { timing, and sequence of a lesson }(*)\end{array}$ & & 11 \\
\hline Coordination & $\begin{array}{l}\text { Effective collaboration and intercommunication among the faculty } \\
\text { members and DO for the school improvement, teaching quality, } \\
\text { and student achievement }\end{array}$ & $\begin{array}{l}\text { Course coordination } \\
\text { Year coordination } \\
\text { Degree coordination }\end{array}$ & 54 \\
\hline Communication & $\begin{array}{l}\text { The process of sharing information, instructions, thoughts, or opinions } \\
\text { to increase understanding between all groups involved in the learning } \\
\text { process }\end{array}$ & & 13 \\
\hline Pedagogical coherence & $\begin{array}{l}\text { Alignment of learning standards and teaching-i.e., how well the } \\
\text { content that students are taught match the academic expectations } \\
\text { described in learning standards }\end{array}$ & & 24 \\
\hline Learning outcomes & $\begin{array}{l}\text { Statements that describe the knowledge, skills, and values that students } \\
\text { should acquire by the end of a class, course, or program }\end{array}$ & & 28 \\
\hline Teaching methodology & $\begin{array}{l}\text { A set of guidelines for designing educational activities and environments } \\
\text { that shapes a curriculum or course }\end{array}$ & $\begin{array}{l}\text { Online model (asynchronous, } \\
\text { synchronous) }\end{array}$ & 158 \\
\hline Online resources & $\begin{array}{l}\text { Resources provided by information and communication technologies } \\
\text { for online teaching }\end{array}$ & & 73 \\
\hline Evaluation & The assessment of students' learning outcomes & & 33 \\
\hline Time management & Proper management of the time spent on the task assignments & & 9 \\
\hline Workload & $\begin{array}{l}\text { Time and effort students and teachers devoted to the educational } \\
\text { process }\end{array}$ & $\begin{array}{l}\text { Student's workload } \\
\text { Teacher's workload }\end{array}$ & 14 \\
\hline Student motivation & $\begin{array}{l}\text { The degree to which students strive to achieve academic goals they } \\
\text { perceive as useful and meaningful }\end{array}$ & $\begin{array}{l}\text { Group cohesion } \\
\text { Sense of belonging }\end{array}$ & 26 \\
\hline Participation & $\begin{array}{l}\text { Student involvement in decision-making processes at the school or } \\
\text { class level, including during the learning activities }\end{array}$ & & 50 \\
\hline Teacher-student relationship & $\begin{array}{l}\text { Relationship of trust that is established between the teacher and the } \\
\text { student leading to a better learning experience }\end{array}$ & & 47 \\
\hline
\end{tabular}

*Course planning must be regarded in the context of a confinement urgently decreed by the country authorities, and applies only to that carried out in the short term for the preparation of specific aspects of teaching 


\section{Course Planning}

This category emerged as a key element among all discussion groups when implementing any change in the teaching process. The sudden shift from face-to-face to distance learning made the adoption of quick and clear guidelines to face the new situation a daunting task. This resulted in the spread of a feeling of uncertainty among students regarding schedules, teaching methodology, assigned tasks, and evaluation criteria. Students expected faculty to provide upfront information and answers on how the course would proceed in the light of the developing events:

"... I felt a constant uncertainty of not knowing the deadlines well enough, nor the weight of the many tasks that were assigned to us. The same applied to some exams..." (student)

"... we had to build our own schedule on the go, because there was really none set ahead of time. Sometimes we were given a one-day notice on a lecture, or even on the same day." (student)

As far as the faculty is concerned, the forced transition to the online format was experienced as an opportunity to reflect on teaching, its means, and its purpose. A "positive" counterpoint amid the dramatic situation:

"Despite all the misfortune, from a teacher's perspective this has become an opportunity. It has forced us to question many things we took for granted. [It has given us] a chance to rethink aspects of teaching that were considered already settled." (faculty)

\section{Coordination}

Coordination was defined as the effective collaboration and intercommunication among the faculty members and DO for the school improvement, teaching quality, and student achievement.

Many students described a feeling of restlessness concerning their academic lives, which was aggravated by the emotional toll the crisis was taking on the students themselves, their relatives, and the society in general.

"... the role played by some subject coordinator teachers was poor... I believe they could have shown more involvement, [they could have] acted more like subject coordinators... and communicated better with us, through the class representatives or by any other means" (student)

“... it was a very very stressful process for everyone to go through because, besides the confinement and everything that was happening, [we had] fears, doubts..." (student)

\section{Communication}

This category was defined as the process of sharing information, instructions, thoughts, or opinions to increase understanding between all groups involved in the learning process.

Outside of the synchronous online classes, the most commonly used channel of communication between faculty and students was e-mail. This channel proved to have its own limitations. In addition, communication was held to a large extent with class representatives exclusively, which left many students feeling that it was insufficient and wishing they had received information first hand. In contrast, initiatives held by some faculty that took advantage of alternative methods of communication such as synchronous chats or asynchronous forums were highly praised.

"Communication, especially in the beginning, was a large area for improvement... particularly among faculty and between faculty and students. There were many [communication] channels and information [provided by these channels] was often misaligned.... there were quite a few misunderstandings..." (student)

\section{Pedagogical Coherence}

Pedagogical coherence was defined as alignment of learning standards and teaching-i.e., how well the content that students were taught matched the academic expectations described in learning standards. This aspect was highlighted above all by students, many of whom expressed the difficulty in relating some of the activities proposed to the corresponding learning objectives. A similar perception was observed regarding the weight or impact of certain tasks in the evaluation process.

“... it was very important for me to understand the importance of many activities that were assigned to us, as well as how they weighed in with regards to the final subject examination. This made things very difficult for me in terms of time management." (student)

\section{Learning Outcomes}

This category refers to statements that describe the knowledge, skills, and values that students should acquire by the end of a class, course, or program.

Faculty and students both expressed the subjective feeling that they accomplished less through distance learning than in face-to-face interaction. This perception was related to challenges met in various areas, such as planning, coordination, and pedagogical coherence. Teachers and students shared the same perspective for a number of competences. 
"... I think that, if things were conducted properly, with clear guidelines easily accessible by everybody, good organization and no last-minute changes, there should not be much problem and results would not have differed much from what is usual." (student)

\section{Teaching Methodology}

Teaching methodology was defined as a set of guidelines for designing educational activities and environments that shape a curriculum or course.

During the initial stages of online teaching deployment, there was confusion and lack of confidence regarding the expected learning outcomes. As far as the class design is concerned, following an orderly sequence of contents, splitting lectures to introduce other activities, allocating time for Q\&A, and making use of engaging activities allowed for immediate feedback between the students and the teacher. In this regard, the activities best rated among students were those that took place live (synchronous).

"Synchronous [learning methods] made it easier for me to interact and address questions and clarifications." (faculty)

“... dealing with clinical cases [the use of synchronous learning methods] obviously encourages you to ask more questions and [obtain] more feedback." (student)

Faculty and students also stressed the importance of being able to keep eye contact in order to "not feel alone in front of a screen," even if it was not constant. Surprisingly, some students described online sessions to enable more participation than face-to-face sessions, suggesting that those with a more introverted personality could feel more confident to make contributions remotely, especially through chat.

"We have been told by many teachers, at some point or another, that they want to see our faces." (student) "Attending class from home alone, without the presence of fellow classmates and teachers, is demotivating. No one to discuss cases side by side with." (student)

\section{Online Resources}

This emergent category was defined as the resources provided by information and communication technologies for online teaching.

The use of online resources was generally well perceived as long as teachers had adequate digital skills to use them properly and could take advantage of their full potential. The diversity in the type of online resources used caused discomfort among some students. Resources that facilitated participation and feedback, particularly those that were delivered synchronously, were among the most welcomed. The same applied to audiovisual resources, such as short video clips showing specific cases or particular clinical aspects.

"The best thing for me has been Collaborate ${ }^{T M}$ [delivered] live, because you can write anything on the screen later or while in class" (student)

"A live [online] class, even better when recorded, is the closest thing to a real class, especially when the teacher encourages interaction. Also, when the class is recorded it makes it easier for me to manage my time and listen to the class whenever I want." (student)

On the other hand, the online platform forums increased the communication and participation of students.

"... also, the good thing about forums is that they allow the students to become teachers, that is ... students themselves respond to the questions posed by their peers. Obviously, [this needs to be] monitored by a teacher." (faculty)

\section{Evaluation}

Evaluation refers to the assessment of students' learning outcomes.

From a teacher's perspective, the need to implement the assessment systems in such a short period of time became a challenge of its own, as it was executed with varying levels of uncertainty, a sense that was often transferred to students.

“... I have been asked to strengthen those activities involving continuous evaluation, which is something I did not have in mind ... and this has added stress to the situation." (faculty)

"They were assigning many tasks to us and we were taking them as they came in, but, in the end, many hardly counted towards the final grade..." (student) "It has become increasingly difficult for me to evaluate students. I have lost the evaluation component tailored to assess individual progress; it is no longer there with this system." (faculty)

\section{Time Management}

This category was defined as proper management of the time spent on the task assignments.

Both students and faculty expressed that online learning is a flexible modality that facilitates time management. This has been emphasized by students of the latest years. One aspect that has been highlighted by students is the decrease of dead time due to waits and commuting. 
"It has helped me to learn to manage my own time." (student)

"... has allowed me to study at my own pace and manage my time, although on occasion I ended up tangled in confusion." (student)

\section{Workload}

Workload was described as the time and effort that students and teachers devoted to the educational process.

Students expressed a general feeling of increased workload, which contributed to the aforementioned stress. Some faculty reacted to their perception of a lack of commitment on behalf of students by assigning them new tasks and projects, perhaps with a relatively small weight in the final grade. Students often considered this burden to be excessive.

"I have lived through university with an intensity that I had never experienced before, much due to the amount of workload [given to us] ... It was of course very difficult at a personal level, given the situation we were going through. But I felt the university was all I could focus on." (student)

At the same time, faculty also pointed out that the sudden transition to online teaching resulted in a greater workload than usual, on top of the high demands of their practice and family obligations. Some of them additionally expressed a lack of digital skills to carry out the switch, which resulted in choosing the simplest resources available.

"I think that a virtual session implies far more work load for a teacher than a standard face-to-face session. Virtual sessions can't last two hours, [therefore] it is very important that students receive good support material to facilitate follow up. [...] Online teaching objectives are very different and involve more work for faculty [...] providing notes if the session takes place online becomes essential for me, very, very important." (faculty)

\section{Student Motivation}

This category was defined as the degree to which students strive to achieve academic goals they perceive as useful and meaningful.

Students reported difficulties in staying motivated. They related this perception to the feeling of uncertainty, lack of coordination, excessive workload, as well as the absence of university social life and decreased relationship with fellow students and faculty, which led to a lower sense of belonging. Some of the faculty also claimed a "feeling of loneliness" due to the absence of direct contact.
Both students and faculty agreed that when teachers are passionate about what they are teaching and stay motivated despite the difficulties of the environment, that boosts student's motivation as well. According to students, the most helpful teaching activities to stay motivated were those that facilitated involvement and student participation, such as case resolution, gamification and the use of questionnaires and surveys.

"I've noticed that subjects that do really well are those where you would notice a teacher behind that stays highly motivated." (student)

"[...] I enjoy attending the campus, talking to my colleagues, and socializing. Because of online [learning] I haven't got together with any of my classmates so far. And I have missed that human contact." (student) "When talking to a screen you lose part of the feedback, not knowing whether [the audience] is following you or not." (faculty)

\section{Participation}

Participation was defined as student involvement in the decisionmaking processes at the school or class level, including during the learning activities.

Students felt that they were left out of many decisions. On the one hand, the need for urgent action required the use of participation channels that differed from those employed under regular circumstances. On the other hand, the crisis situation brought to test the level of endorsement of the class representatives, which was occasionally questioned by the student community at large due to miscommunication.

$$
\begin{aligned}
& \text { “... a meeting was held between faculty and students to } \\
& \text { reach an agreement ...things have been running pretty } \\
& \text { smooth ever since...." (student) } \\
& \text { "... if there was a teacher reading a PowerPoint pres- } \\
& \text { entation, no one talked, no one asked questions. But if } \\
& \text { you had read the support material because the teacher } \\
& \text { had uploaded a summary beforehand, you were much } \\
& \text { more engaged [in class], asking questions and [provid- } \\
& \text { ing] feedback." (student) }
\end{aligned}
$$

\section{Teacher-Student Relationship}

This category was defined as the relationship of trust that is established between the teacher and the student, leading to a better learning experience.

Students and faculty have missed the close teacher-student relationship in class and outside the classroom, as well as the social life on campus. 
"The interaction with students is very different, ... I have experienced it with a level of sadness, like a loss... it's not the same." (faculty)

"Online training implies social isolation. ... it was required in this case, of course, but being able to contact face-to-face with your peers and teachers is a different ball game" (student)

\section{Triangulation of Qualitative and Quantitative Data}

Overall, the triangulation integrating analysis of qualitative and quantitative data showed a high degree of agreement. Poor course planning, quick adoption of new teaching methodologies, and short notice for assignments generated uncertainty and stress in students, as well as a lack of a clear understanding of the connection between tasks and learning objectives. These perceptions were recurrently highlighted by students in focus groups and corroborated by the low ratings given in the survey to the categories of course planning (mean score of 2.6 out of 5) and pedagogical coherence (2.6/5). Students' dissatisfaction with learning outcomes derived from online teaching was generally expressed in focus group discussions but only partially confirmed quantitatively: while students from third to fifth year felt unsatisfied (2.7/5), those from first and second year had an acceptable perception (3.1/5). On the other hand, there was agreement in the favorable opinion of students about the use of online synchronous learning tools, both collected in discussions and in the survey (3.9/5). Similarly, excessive workload, a major issue that was extensively discussed, correlated with the lowest score obtained for any category in the survey $(0.7 / 5)$. The difficulty to stay motivated was another point arisen in discussions that reflected in a low score for the category of motivation (2.3/5). No contradiction was also found between students' critical feedback on the limited online teacher-student relationship given in the focus groups and in the survey (2.1/5). Significantly, while low participation was recurrently pointed out by students in focus groups, scoring of participation obtained in the survey was dependent on the teaching methodologies implemented (master classes: 2.9/5; case methods: 3.4/5). Triangulation of results helped us to find out the strengths and weaknesses of online teaching from the perspective of both students and teachers, as shown in Table 2.

Table 2 Main perceptions of students and faculty about online versus traditional face-to-face teaching

\begin{tabular}{|c|c|c|c|}
\hline Categories & Aspects & Students & Teachers \\
\hline Course planning & Limitations & -Frequent improvisation in teaching & \\
\hline Coordination & Limitations & -Changes in the calendar/non-compliances & \\
\hline Pedagogical coherence & Limitations & $\begin{array}{l}\text {-Understanding the pedagogical coherence of } \\
\text { new assignments }\end{array}$ & \\
\hline Learning outcomes & Strengths & & $\begin{array}{l}\text {-Encourages reflection and focusing in the most } \\
\text { important aspects }\end{array}$ \\
\hline Teaching methodologies & Limitations & & $\begin{array}{l}\text {-Adapting to the dynamics of synchronous online } \\
\text { sessions (multitasking) }\end{array}$ \\
\hline Online resources & Limitations & & -Lack of digital skills \\
\hline Time management & Strengths & $\begin{array}{l}\text {-Better use of time } \\
\text {-Better conciliation with social life } \\
\text {-Learning at your own pace (through teacher- } \\
\text { supplied resources, such as recorded classes, } \\
\text { supplementary notes) }\end{array}$ & -Work-life conciliation (e.g., fewer trips) \\
\hline Workload & Limitations & -Excessive workload & $\begin{array}{l}\text {-Increased workload } \\
\text {-Adapting materials in a short period of time }\end{array}$ \\
\hline Motivation & Limitations & $\begin{array}{l}\text {-Remaining motivated } \\
\text {-Loss of social life in campus }\end{array}$ & \\
\hline \multirow[t]{2}{*}{ Participation } & Strengths & -Greater learning autonomy & \\
\hline & Limitations & -Participating actively & $\begin{array}{l}\text {-Loneliness (i.e., during online sessions) } \\
\text {-Obtaining feedback from students }\end{array}$ \\
\hline \multirow[t]{2}{*}{ Teacher-student relationship } & Strengths & -Direct contact in synchronous sessions & $\begin{array}{l}\text {-Increased diversity in ways of communicating } \\
\text { with students }\end{array}$ \\
\hline & Limitations & -Preserving the student-teacher relationship & $\begin{array}{l}\text {-Student personal knowledge (needs, achievements, } \\
\text {...) }\end{array}$ \\
\hline
\end{tabular}




\section{Discussion}

This study identified 13 strongly interconnected categories that should be considered for a successful implementation of online medical education in uncertain scenarios like the current COVID-19 pandemic. Four categories played an organizational role (course planning, coordination, communication, and pedagogical coherence) while the remaining nine were directly associated with the processes of teaching and learning (learning outcomes, teaching methodology, online resources, evaluation, time management, workload, student motivation, participation, and teacher-student relationship).

Traditionally, medical students have mostly shown positive attitudes towards online teaching $[14,15]$. Before the pandemic, a number of studies had underlined the benefits of incorporating digital interactive tools to achieve satisfaction and engagement with medical students. Use of short video tutorials instead of long lectures, as well as games, polls, and other technologically enhanced resources, was reported to increase medical student engagement [16, 17]. Synchronic online lectures were considered to open opportunities for some students to ask and answer questions in a less intimidating environment, thus encouraging engagement from those who would not otherwise participate in a live lecture [18]. In addition, the online modality was shown to enable individualized teacher feedback to students, improving the commonly limited feedback that can be provided in large group face-to-face sessions [19]. Conversely, distance learning observed to reduce student-teacher and student-student interaction, and thus impair engagement [20].

The strengths and drawbacks of online teaching were dramatically confirmed during the pandemic. The general opinion of the students that we surveyed about this teaching modality was only "acceptable." Our results were partially aligned with those reported in recent studies. A survey with 70 first-year students at a school of Medicine in Israel described that a wide majority of them (88.6\%) rated their overall satisfaction as high or very high on a 5-point Likert-type scale, and none scored it as low or very low [21]. Another single-center survey with 340 medical students from Saudi Arabia showed that a predominant proportion of responders $(76.2 \%)$ qualified their virtual learning experience as "not bad" while a minority of them (23.8\%) considered it to be "bad" [22]. In contrast, a UK national survey with 2,721 students of Medicine estimated an average of 1.69/5 scored for preference for online teaching, suggesting that most students preferred face-to-face training [23]. Similarly, among 652 students in their clinical clerkship years from all medical schools in Jordan, a low proportion (26.8\%) of them were satisfied with distance learning [24]. Shifting from face-to-face to online learning in medical education is a challenge by itself, even in scenarios of normality
[25]. We speculate that concerns expressed by students in our and other studies may primarily derive from the sudden transition made in most schools of Medicine to this teaching modality, and not from an aprioristic negative perception. Other external factors such as the severity of health, social, and economic repercussions of the pandemic in each specific geographical area could also contribute to relieving or aggravating unfavorable attitudes of medical students towards online education.

Our results revealed that synchronous modes of online teaching, especially those based on clinical case studies, gained a reasonable degree of student satisfaction, as indicated by qualitative data and survey scores (synchronous sessions: 3.9/5; case studies: 3.4/5). A survey among 162 fifth-year medical students at a Saudi Arabian medical school reported that $82 \%$ of responders were highly satisfied with case-based discussion through web video conferencing versus $18 \%$ that were not [26]. In a similar way, a focus group qualitative study with 60 medical students from the same country described a general satisfaction with synchronized online learning, although it was perceived to be more effective for some theoretical subjects [27]. Interestingly, we observed slightly better perceptions of online teaching in students enrolled in first and second years (average overall satisfaction score: $3.1 / 5$ ), which include a majority of basic sciences courses, than in students enrolled in third, fourth, and fifth years (2.7/5). This finding is consistent with concerns commonly identified among third- to fifthyear students about their decreased clinical skill training as a consequence of the loss of in-person experience during their readjusted clerkships [28-30]. Altogether, these evidences seem to point to a higher suitability of online teaching in preclinical years compared to later academic years in which physical contact with patients and acquisition of practical skills become essential.

A more autonomous and efficient use of time was another positive aspect of online teaching that was repeatedly underlined by students in focus group discussions. Our identification of improved time management associated with virtual teaching agreed with previous literature. The benefits of using digital resources for efficient learning in medical education had already been described in the pre-pandemic period [31]. Recently, UK medical students cited time saved on travelling (19.8\%), flexibility (19.5\%), ability to learn at one's own pace (18.6\%), convenience (15.8\%), and cutting expenses $(14.2 \%)$ as the greatest perceived benefits of online teaching for students [23]. In a similar way, almost two-thirds of 104 first- and second-year students surveyed in a US medical school stated that increased flexibility was the best part of remote teaching [32].

This study identified strong upstream organizational barriers as well as downstream obstacles for a smooth 
shift to online teaching. Adequate transition was seriously undermined by the pandemic educational emergency, and was constrained to a few days available to redesign and implement key organizational and operational aspects, such as planning and coordination of activities, allocation of hardware and software resources, establishment of communication channels between faculty and students, and adaptation of teaching contents, methodologies, and evaluation systems [33]. In this regard, faculty members of 14 schools of Medicine in UK and Ireland highlighted that the scarce time left to develop new online resources was the major challenge posed by the pandemic [34]. As a consequence, most of our students experienced perceptions of decreased learning performance, increased workload, lack of technical resources, and suboptimal coordination, participation, and communication. Similar feelings and views have also been shared to a greater or lesser extent by students and faculty at other medical schools across different countries during the pandemic. A survey that was carried out with 804 students of all years at Polish medical schools indicated that the lack of interactions with patients (70\%), inadequate IT infrastructure and connectivity (54\%), and reduced interaction with the teacher were the main disadvantages of e-learning [35]. The majority of 620 respondents to another survey conducted in that country identified unsatisfactory contents $(59.2 \%)$, technical issues (22.9\%), difficulties engaging (19.4\%), and poor organization (18.9\%) as major complaints [36]. Students across all years from UK medical schools pointed out that the principal shortfalls were family distraction (26.8\%), limited internet connection (21.5\%), and timing of tutorials (17.3\%) [23], whereas Jordan medical students highlighted poor interaction with instructors $(62.1 \%)$ and classmates (57.2\%), and impaired instruction (48.3\%) [24].

Faculty and students globally expressed their feeling that learning outcomes had not been fully met. This result is intriguing, since we have compared grades obtained by students exposed to online versus in-person teaching and found no significant difference in learning performance. Similarly, a recent systematic review suggested that online learning is not less effective than face-to-face learning in medical education [37]. In turn, late surveys of both medical students in the pre-clinical and the clinical stages have collected predominantly negative perceptions about online quality of instruction [28-30, 32]. Detrimental learning experiences could mostly be related to low digital skills of faculty and frequent technical problems encountered during synchronous and asynchronous sessions, as reported in diverse studies [23, 27, 32, 35, 36].

The results presented in this single-center study may not be applicable to other contexts and could have been influenced by the particular cultural environment in which the study was conducted, as well as the specific socioeconomic repercussions of the pandemic in our geographical area. A second limitation refers to quantitative analysis. Although the level of participation in the survey was acceptable, as we collected responses from up to half of the number of students enrolled, the possibility of self-selection bias cannot be discarded.

In conclusion, this study identified an "acceptable" perception of the sudden transition to online teaching in the majority of the students surveyed in our medical school during the COVID-19 crisis. Promoting student motivation and participation at all levels were the main lessons learned for enhancing online learning and teaching experiences of students and faculty in undergraduate medical education. Key strategic elements to reach this goal are, among others, planning, coordination, communication, and pedagogical coherence.

Supplementary Information The online version contains supplementary material available at https://doi.org/10.1007/s40670-022-01518-9.

Acknowledgements We would like to thank the medical students and faculty members at UIC School of Medicine and Health Sciences who participated in the focus and nominal group discussions, respectively, as well as the medical students who responded to the survey.

Author Contribution Conceptualization and methodology: MV, ME, MG, AB. Qualitative and quantitative data collection: MV, ME. Quantitative data analysis: PB. Mixed methods analysis: MV, ME, MG. Writing-original draft preparation: MV, ME, MG, PB, PM. Review and approval of final draft: $\mathrm{MV}, \mathrm{ME}, \mathrm{MG}, \mathrm{PB}, \mathrm{PM}, \mathrm{AB}$.

\section{Declarations}

Ethics Approval The study was approved by the Ethics and Research Committee of the study site and written informed consents were obtained from all participants prior to initiation.

Conflict of Interest All authors state that they are faculty members at Universitat Internacional de Catalunya.

\section{References}

1. WHO. Public Health Emergency of International Concern declared. Available from: https://www.who.int/emergencies/diseases/novelcoronavirus-2019/events-as-they-happen. [Accessed 21 Oct 2021].

2. European Centre for Disease Prevention and Control. COVID-19 situation update worldwide, as of week 11, updated 21 October 2021. Available from: https://www.ecdc.europa.eu/en/geographic al-distribution-2019-ncov-cases. [Accessed 21 Oct 2021].

3. Ferrel MN, Ryan JJ. The impact of COVID-19 on medical education. Cureus. 2020;12:e7492.

4. Rolak S, Keefe AM, Davidson EL, Aryal P, Parajuli S. Impacts and challenges of United States medical students during the COVID-19 pandemic. World J Clin Cases. 2020;8(15):3136-41.

5. Rose S. Medical student education in the time of COVID- 19. JAMA. 2020;323(21):2131-2. 
6. Creswell JW, Plano Clark VL. Designing and conducting mixed methods research. Thousand Oaks, California: Sage Publications; 2011.

7. Creswell JW. A concise introduction to mixed methods research. Thousand Oaks, California: SAGE publications; 2014.

8. Schifferdecker KE, Reed VA. Using mixed methods research in medical education: basic guidelines for researchers. Med Educ. 2009;43(7):637-44.

9. Colom AJ, Nuñez L. [The (de)construction of the pedagogical knowledge: new perspectives in the theory of education] (Spanish). Barcelona: Paidós; 2002.

10. Posada ÁR. [Higher education based on competences, interdisciplinarity, and student autonomous work] (Spanish). Revista Iberoamericana De Educación. 2004;35(1):1-33.

11. Martinez MM. [Training for citizens and higher education] (Spanish). Revista Iberoamericana de Educación. 2006;42(1):85-102.

12. Bisquerra R. [Methodolody of research in education] (Spanish). Madrid: Editorial La Muralla; 2004.

13. Brotons P, Virumbrales M, Elorduy M, Mezquita P, Graell M, Balaguer A. [Perceptions of students confined by the COVID-19 pandemic on distance learning in medicine] (Spanish). Rev Med Chil. 2020;148(10):1461-6.

14. Scott K, Morris A, Marais B. Medical student use of digital learning resources. Clin Teach. 2018;15(1):29-33.

15. Baldwin A, Webb R, Gainsborough N, Howlett D, Inglis C. Provision of electronic learning resources by UK medical schools for final year students. Med Teach. 2011;33(4):325-7.

16. Tang B, Coret A, Qureshi A, Barron H, Ayala AP, Law M. Online lectures in undergraduate medical education: scoping review. JMIR Med Educ. 2018;4(1):e11.

17. Kay D, Pasarica M. Using technology to increase student (and faculty satisfaction with) engagement in medical education. Adv Physiol Educ. 2019;43(3):408-13.

18. Ni AY, Ya NA. Comparing the effectiveness of classroom and online learning: teaching research methods. J Public Aff Educ. 2013;19:199-215.

19. Herbert C, Velan GM, Pryor WM, Kumar RK. A model for the use of blended learning in large group teaching sessions. BMC Med Educ. 2017;17(1):197.

20. Kunin M, Julliard KN, Rodriguez TE. Comparing face-to-face, synchronous, and asynchronous learning: postgraduate dental resident preferences. J Dent Educ. 2014;78(6):856-66.

21. Sandhaus Y, Kushnir T, Ashkenazi S. Electronic distance learning of pre-clinical studies during the COVID-19 pandemic: a preliminary study of medical student responses and potential future impact. Isr Med Assoc J. 2020;8(22):423-7.

22. Ibrahim NK, Al Raddadi R, AlDarmasi M, Al Ghamdi A, Gaddoury M, AlBar HM, et al. Medical students' acceptance and perceptions of e-learning during the COVID-19 closure time in King Abdulaziz University. Jeddah J Infect Public Health. 2021;14(1):17-23.

23. Dost S, Hossain A, Shehab M, Abdelwahed A, Al-Nusair L. Perceptions of medical students towards online teaching during the COVID-19 pandemic: a national cross-sectional survey of 2721 UK medical students. BMJ Open. 2020;10(11):e042378.

24. Al-Balas M, Al-Balas HI, Jaber HM, Obeidat K, Al-Balas H, Aborajooh EA, et al. Distance learning in clinical medical education amid COVID-19 pandemic in Jordan: current situation, challenges, and perspectives. BMC Med Educ. 2020;20(1):341.

25. O'Doherty D, Dromey M, Lougheed J, Hannigan A, Last J, McGrath D. Barriers and solutions to online learning in medical education - an integrative review. BMC Med Educ. 2018;18(1):130.

26. Fatani TH. Student satisfaction with videoconferencing teaching quality during the COVID-19 pandemic. BMC Med Educ. 2020;20(1):396. 2020.

27. Khalil R, Mansour AE, Fadda WA, Almisnid K, Aldamegh M, Al-Nafeesah A, et al. The sudden transition to synchronized online learning during the COVID-19 pandemic in Saudi Arabia: a qualitative study exploring medical students' perspectives. BMC Med Educ. 2020;20(1):285.

28. Kelly EL, Casola AR, Smith K, Kelly S, de la Cruz MSD. A qualitative analysis of third-year medical students' reflection essays regarding the impact of COVID-19 on their education. BMC Med Educ. 2021;21(1):481.

29. Kim SM, Park SG, Jee YK, Song IH. Perception and attitudes of medical students on clinical clerkship in the era of the coronavirus disease 2019 pandemic. Med Educ Online. 2020;25(1):1809929.

30. Byrnes YM, Civantos AM, Go BC, McWilliams TL, Rajasekaran K. Effect of the COVID-19 pandemic on medical student career perceptions: a national survey study. Med Educ Online. 2020;25(1).

31. Maloney S, Chamberlain M, Morrison S, Kotsanas G, Keating JL, Ilic D. Health professional learner attitudes and use of digital learning resources. J Med Internet Res. 2013;15(1):e7.

32. Shahrvini B, Baxter SL, Coffey CS, MacDonald BV, Lander L. Pre-clinical remote undergraduate medical education during the COVID-19 pandemic: a survey study. Res Sq [Preprint]. 2020. doi: https://doi.org/10.21203/rs.3.rs-33870/v1.

33. Sánchez González M. [To design/adapt training programs to e-learning: key points on the UNIA model] (Spanish). Available from: https:// dspace.unia.es/bitstream/handle/10334/5320/Sanchez_Maria2020-21_ Dise \%c3\%blar.pdf?sequence $=1 \&$ is Allowed=ydspace.unia.es $/$ handle/ 10334/5320. [Accessed 21 Oct 2021].

34. Longhurst GJ, Stone DM, Dulohery K, Scully D, Campbell T, Smith CF. Strength, weakness, opportunity, threat (SWOT) analysis of the adaptations to anatomical education in the United Kingdom and Republic of Ireland in response to the COVID-19 pandemic. Anat Sci Educ. 2020;13(3):301-11.

35. Bączek M, Zagańczyk-Bączek M, Szpringer M, Jaroszyński A, Wożakowska-Kapłon B. Students' perception of online learning during the COVID-19 pandemic: a survey study of Polish medical students. Medicine (Baltimore). 2021;100(7):e24821.

36. Pokryszko-Dragan A, Marschollek K, Nowakowska-Kotas M, Aitken $\mathrm{G}$. What can we learn from the online learning experiences of medical students in Poland during the SARS-CoV-2 pandemic? BMC Med Educ. 2021;21(1):450.

37. Pei L, Wu H. Does online learning work better than offline learning in undergraduate medical education? A systematic review and meta-analysis. Med Educ Online. 2019;24:1666538.

Publisher's Note Springer Nature remains neutral with regard to jurisdictional claims in published maps and institutional affiliations. 